\title{
Two Millian Arguments: Using Helen Longino's Approach to Solve the Problems Philip Kitcher Targeted with His Argument on Freedom of Inquiry
}

\author{
Jaana Eigi \\ Department of Philosophy, University of Tartu
}

Philip Kitcher argued that the freedom to pursue one's version of the good life is the main aim of Mill's argument for freedom of expression. According to Kitcher, in certain scientific fields, political and epistemological asymmetries bias research toward conclusions that threaten this most important freedom of underprivileged groups. Accordingly, Kitcher claimed that there are Millian grounds for limiting freedom of inquiry in these fields to protect the freedom of the underprivileged. I explore Kitcher's argument in light of the interpretation Helen Longino gave to Mill's argument. She argued that free critical dialogue in the community allows bias to be overcome, through intersubjective criticism of hypotheses and the background assumptions that frame them. I suggest that Longino's approach allows for the identification of the fundamental problems of the research programs Kitcher targeted, and for the rejection of their claims to knowledge. Thus it is possible to address Kitcher's problem without limiting freedom of speech.

Keywords: freedom of speech, Mill, Kitcher, Longino, social consequences of research

\section{Introduction}

In this paper, I focus on Philip Kitcher's argument concerning freedom of scientific inquiry that Kitcher based on his interpretation of John Stuart Mill's argument for freedom of expression. ${ }^{1}$ The argument, first presented

Corresponding author's address: Jaana Eigi, Department of Philosophy, Institute of Philosophy and Semiotics, University of Tartu, Jakobi 2, Tartu, 51003, Estonia. Email: jaana.eigi@ut.ee.

1 Mill's main book on knowledge and the scientific method is System of Logic (1843); the argument for freedom of speech is presented in Mill's classic political essay On Liberty (1859). Besides Kitcher and Longino, there are other philosophers of science who have 
in a journal article (1997), was later integrated in Kitcher's discussion of the ideal of "well-organised science" (2001). Kitcher argued that there are cases in which the restriction of freedom of expression can be justified in the spirit of Mill's defence of the ultimate value of individual freedom. Accordingly, Kitcher proposed a Millian argument against unrestricted freedom of inquiry in the fields of research whose conclusions are likely to threaten this fundamental freedom of certain individuals. This argument constitutes a part of Kitcher's attempt to develop a philosophy of science with greater emphasis on its social consequences, such as questions of fairness and democracy. I explore Kitcher's argument through the lens of another philosopher's work on Mill, suggesting that Helen Longino's account that approaches free critical dialogue as the foundation for the creation of knowledge (Longino 1990, 2002) could address the problems Kitcher targeted with his argument, without restricting free speech.

In the next section of the paper, in order to provide the background for Kitcher's and Longino's arguments, I briefly describe Mill's argument regarding freedom of expression, and some aspects of his conception of knowledge. In the third section, I summarise Kitcher's Millian argument that justifies restrictions of freedom of inquiry in particular fields of research. The fourth section introduces some existing criticisms of Kitcher's argument and characterises the place of my own argument in this context. In the fifth section, I describe Longino's interpretation of the role of the Millian ideal in justification of knowledge claims, and her account of objectivity. The sixth section shows how Longino's approach can be applied to the cases Kitcher described. I argue that drawing on her account it is possible to address the issue of negative social consequences of particular problematic lines of research and to avoid the problems in connection with the restrictions Kitcher proposed. The seventh section addresses several criticisms that can be raised against this application of Longino's account.

\section{Mill's argument}

Mill presented his argument regarding freedom of thought and speech in the second chapter of On Liberty. When describing the benefits of free discussion, and the negative consequences of suppressing alternative opinions, Mill suggested the following:

1. If the popular opinion is false, the availability of alternatives and free discussion of them helps to overcome falsity and discover the truth. 
2. If the popular opinion is true, the presence of contrary opinions and the necessity to reply to them facilitates a deeper understanding of the content and justifications of the true opinion. Further, discussion keeps perception of the truth vivid; without it, opinions tend to become dogmatic.

3. Most opinions, even true ones, are not the whole truth-discussing alternative opinions helps to discover missing aspects of the truth and to make our understanding of it fuller.

These arguments presuppose that human knowledge is fundamentally fallible-there is no way to make certain that opinions currently believed to be true are indeed the truth, and Mill passionately condemned pretences to infallibility (see, for instance, Mill 1978, 16-17). At the same time, Mill's arguments reveal his optimism about the human ability to improve existing knowledge by means of free discussion. People are able to correct their mistakes, and free discussion is an adequate method for doing so and gradually approaching the truth.

[T] he source of everything respectable in man either as an intellectual or as a moral being, [is] namely, that his errors are corrigible. He is capable of rectifying his mistakes by discussion and experience. Not by experience alone. There must be discussion to show how experience is to be interpreted. Wrong opinions and practices gradually yield to fact and argument; but facts and arguments, to produce any effect on the mind, must be brought before it. [... [T] he only way in which a human being can make some approach to knowing the whole of a subject is by hearing what can be said about it by persons of every variety of opinion, and studying all modes in which it can be looked at by every character of mind. (Mill 1978, 19)

A conception of knowledge that can be reconstructed on the basis of these arguments seems to be "proto-Popperian" (Ryan 1998, 509), as it stresses the need to expose knowledge claims to possible refutations. ${ }^{2}$

\section{Kitcher on freedom of speech and fairness for the underprivi- leged}

In his Millian argument, Kitcher focused on cases in which an appeal to Mill's argument is made to protect certain areas of controversial research with far-reaching social consequences, such as research into the biological

2 Ryan noted that regardless of that, Mill's argument was not primarily aimed at scientific ideas. Longino (2002, 3-4), on the contrary, argued that original Mill's argument was meant to include science; she named Mill among the predecessors of her own philosophy of science. 
basis of sex and race differences, for instance, human sociobiology. Those who appeal to Mill's argument in such cases seem to presuppose that it supports unrestricted freedom of expression as the ultimate good. Kitcher admitted that his earlier arguments also did not question the value of freedom of expression (Kitcher 1997, 280). In this paper I focus on another interpretation of Mill's argument Kitcher has since suggested.

In this new interpretation, Kitcher sees the freedom of the individuals to freely pursue the mode of life they have freely chosen as the ultimate good that Mill's argument defends: "The only freedom which deserves the name is that of pursuing our own good in our own way, so long as we do not attempt to deprive others of theirs or impede their efforts to obtain it" (Mill $1978,12)$. Kitcher $(2001,95)$ used this quote to sum up the aim of Mill's argument and stressed that Mill defended freedom of speech as necessary for this general aim. Kitcher argued that in certain cases and for certain individuals, unlimited freedom of inquiry can jeopardise the fundamental freedom to pursue one's version of good life. Accordingly, in such cases certain restrictions on freedom of inquiry are justified. This is the central idea of Kitcher's argument.

Kitcher identified several conditions that make his argument applicable (Kitcher 2001, 96-98). The first condition is related to the social context of research. Research takes place in society in which there are considerable inequalities and members of certain underprivileged groups have a lower quality of life, and less chance at achieving good life. Inequalities are partially caused by residual beliefs about the natural inferiority of members of these groups-such beliefs are mostly repudiated but still retain some influence. If research provides conclusions that reinforce such beliefs, it is likely to endanger the chances of the underprivileged to pursue their life projects by diminishing their sense of self-worth and worsening their social climate.

Research conclusions are likely to be interpreted as supporting the inegalitarian beliefs if two further conditions apply, which Kitcher called "political and epistemic asymmetries".

Political asymmetry describes the situation in which:

1. When research supports hypotheses that members of underprivileged groups are less suited to socially privileged positions, old beliefs are revived. Refutation of such hypotheses does not lead to considerable eradication of residual old beliefs.

2. Society-wide acceptance of such inegalitarian conclusions leads to a further reduction in quality of life for the underprivileged. Quality of life for underprivileged groups does not improve unless there is a considerable eradication of residual beliefs. 
Epistemic asymmetry occurs when inegalitarian conclusions are perceived as better justified than can be warranted while refutations of inegalitarian conclusions are perceived as less justifiable than can be warranted. Thus, even when evidence is indecisive, epistemic asymmetry produces unjustified support from researchers and the public for inegalitarian conclusions. Inegalitarian conclusions have an unfair advantage when competing with alternative views. Because Mill's ideal presupposes that ideas compete with each other on equal terms, Kitcher argued that, in practice, the Millian arena falls short of the ideal (Kitcher 1997, 291).

In order to apply Kitcher's argument to particular kinds of research, it is necessary to demonstrate that the research programs in question generates ideas that are relevant to socially entrenched beliefs concerning underprivileged groups, that their interpretations are shaped by asymmetries, and that their conclusions are likely to be seen as supporting inegalitarian beliefs. According to Kitcher (2001, 98-100), for instance, some debates in human sociobiology and human behavioural genetics satisfy these conditions. Overall, such research negatively affects the chances of underprivileged to live a good life of their own choosing. Therefore, Kitcher argued, there are grounds for restricting freedom of inquiry in these areas in order to protect the fundamental freedom of the underprivileged.

Kitcher $(2002,105-108)$ discussed the issue of implementing restrictions on freedom of inquiry, and concluded that a direct ban would be counterproductive. Among other effects, political and epistemic asymmetries prevent public recognition of unfair bias toward inegalitarian conclusions. Accordingly, a ban on certain lines of research is likely to be perceived as an attempt to silence legitimate research for political motives, which, in turn, could reinforce existing prejudices. One possible solution is for scientists to treat the conclusion of Kitcher's argument as a moral imperative, wherein they would have a duty to refrain from certain inquiries. However, Kitcher noted that this is an unrealistic solution, since the current social climate and political/epistemological asymmetries create incentives for scientists to pursue research projects that resonate with residual inegalitarian beliefs and generate considerable public interest. Kitcher stressed the need to analyse the functioning of the Millian arena in different areas of inquiry, in order to identify its failures and possibilities for improvement. In some fields of research, where the potentially negative social consequences are great and biases inescapable, according to Kitcher, there is just cause not to pursue some lines of inquiry. 


\section{Some existing criticisms concerning Kitcher's argument}

Kitcher's approach to the regulation of research has provoked several responses. Robert Talisse and Scott Aikin (2007) argued that restricting freedom of inquiry in particular research areas would have negative consequences in terms of both social fairness and the progress of science. If conscientious researchers accept Kitcher's argument, and abstain from research into race and sex differences, these areas may be abandoned to those who do not acknowledge Kitcher's argument. Among them are likely to be those who do not believe that current inequalities are unfair but rather justify them on the basis of their own beliefs about innate inferiority of members of underprivileged groups. Their research is overwhelmingly likely to deliver conclusions that influence the social climate for the underprivileged negatively. In other words, the restrictions might actually worsen the situation for the underprivileged. ${ }^{3}$ A duty to abstain from particular research topics, given the global character of science and the unpredictability of research developments and connections, could paralyse scientists' ability to plan and carry out any long-term research. Though I believe that Talisse and Aikin made a valid point, they did not propose a solution to Kitcher's concern about the negative social value of certain research programs.

James Brown suggested that while he does not see a problem in banning certain lines of research, a more promising strategy would be to ensure that scientific community is "suitably diverse" (Brown 2004, 605). According to Brown's argument, if underprivileged groups are adequately represented among scientists, biased research will be criticised internally, and the overall quality of research will improve without the need to restrain any lines of inquiry. K. Brad Wray (2001) also suggested that mutual criticism in diverse epistemic communities would prevent individual or group biases from determining the results of scientific research. (Unlike Kitcher, Wray argued that biases characterise all areas of research, not just certain problematic ones.)

My own argument, based on the work of Helen Longino, also focuses on diversity as a crucial factor for addressing bias in socially consequential research. Employing Longino's social epistemology, I attempt to develop this line of argumentation further in two respects. Firstly, her account of scientific objectivity, based on critical interactions in diverse communities, can be applied to research programs in order to analyse the nature of their problems and to evaluate their claims to knowledge. Secondly, Longino saw the social

3 Kitcher (2007) argued that negative consequences would not be as widespread and drastic: in some cases the abandoned research would not be undertaken by anyone else and so no negative consequences would follow; in other cases the backlash would be counteracted by conscientious researchers criticising the fallacies of biased research. 
organisation of communities as directly relevant to effectively preventing biases. I suggest that in order to address the problems that Kitcher identified scientific research should be structured in such a way that maximises critical dialogue in scientific community.

\section{Longino on background assumptions and transformative crit- icism}

I suggest, based on Kitcher's descriptions of problematic research areas and their social consequences, that they can be seen as depending on certain general assumptions, including:

1. Members of underprivileged groups all share certain biological traits; these traits are more important than those they share with the rest of the population or the variability between the group members.

2. Abilities and social achievements can be directly linked to one's biological makeup.

3. Given a certain makeup, only limited development of the abilities in question is possible.

4. Scientific findings in these areas can, and should, be translated into social policy.

These assumptions do not constitute a list of the necessary and sufficient conditions that identify problematic programs. Rather, they provide a general framework that makes such programs possible. In other words, they create the context in which these approaches and interpretations make sense. None of the assumptions is self-evidently true; however, they sometimes escape critical scrutiny if discussion focuses on particular hypotheses rather than the assumptions that provide a framework for them.

Longino called such enabling assumptions 'background assumptions' (Longino 1990, 43). They form the background for linking data and hypotheses, thus solving the problem of underdetermination (the logical gap between data and hypotheses). Hypotheses can only be justified as supported by some data in context of background assumptions that establish the relevance of the data for hypotheses. But this account of justification on the basis of background assumptions creates the problem of justifying the assumptions themselves. How is it possible to prevent the influence of scientists' subjective biases on their background assumptions? This problem is particularly acute because background assumptions are typically invisible for those who hold them. Longino turned to Mill to address this issue. 
Longino claimed that she shares with Mill the belief about "the necessity of critical interaction for the integrity of knowledge" (Longino 2002, 4). According to Longino (1990, 64-76), science is a collective activity that necessarily requires interaction between practitioners. It is only through critical interactions between community members that a certain degree of objectivity is possible. In order to be accepted as communal knowledge, hypotheses have to survive criticism from multiple points of view. In this process, the biases and idiosyncrasies of individual scientists can be checked and eliminated.

Relevant criticism of a hypothesis can be suggested by community members on several levels. While evidential criticism focuses on experimental and observational concerns, conceptual criticism deals with theoretical and meta-theoretical issues, including the relevance of certain data for particular hypotheses. It is the latter form of criticism that targets background assumptions and thus plays a crucial role in preventing the influence of subjective biases. It is important to stress that explication of the background assumptions does not by itself prove the research is flawed ${ }^{4}$-all research is shaped by some assumptions. It is those assumptions that are left unchecked by communal criticism that pose a problem. When exposed, problematic assumptions have to be defended, modified or abandoned-Longino (1990, 73) called this kind of criticism 'transformative'. Diversity of points of view and freedom of discussion are crucial for effective criticism. The availability of alternative hypotheses and approaches can reveal the dependence of particular hypotheses on certain background assumptions and thus provide opportunity for their critical discussion.

Scientific objectivity in this approach requires the kind of debate Mill envisaged in his work. Free debate ensures that opinions that are deemed communally unacceptable are eliminated and (tentatively) accepted ones are developed further through critical discussion. However, the efficiency of such a discussion may be hindered if there are limited venues for the presentation of criticism, or if the community is not particularly responsive to it. Longino (1990, 76-81) suggested a set of criteria for transformative criticism as the basis for judging a community's ability to support production of objective knowledge:

1. the availability of recognised public venues for criticism;

2. shared standards for judging the relevance of both criticisms and reactions to them (these standards are not fixed but are also open for communal criticism and may be modified);

${ }^{4}$ Kitcher $(1997,298)$ seemed to presuppose that. 
3. the community's response to criticism (uptake);

4. and the equality of intellectual authority among the participants.

Longino $(2002,129)$ noted that although the criteria may seem trivial, it is important to acknowledge the extent to which social organisation of science can discourage criticism. For instance, in research communities, the pressure to produce positive results, and issues such as secrecy and the privatisation of results, are factors that can prevent criticism from being presented widely and taken seriously. In order to support efficient criticism, attention to the social organisation of science is therefore as important as attention to diversity (or lack thereof) and the representation of different groups in scientific community.

Longino's criteria offer a framework for assessing how closely a research community approaches the Millian ideal. Her contextual account of justification explains in turn why this ideal has crucial epistemic importance. What can this approach say about the research areas Kitcher criticised?

\section{A Longinian solution}

According to Longino (2002, 134), a community qualifies as knowledgeproducing only to the degree it satisfies the criteria for transformative criticism. If there is no efficient criticism and no response to it, the community does not qualify as knowledge-productive and the outcomes of its practices do not qualify as knowledge (see, e.g., Longino 2002, 135-136 for the definition of epistemic acceptability and 156-162 for examples of its application to criticise certain claims to knowledge).

Kitcher characterised a considerable part of the past and present work in human sociobiology and behavioural genetics as showing precisely this kind of blindness to relevant empirical and conceptual criticism, and obduracy in following the same programs with the same assumptions as if unchallenged (Kitcher 1985 is entirely dedicated to criticism of several influential sociobiological programs; see also Kitcher 2001, 99-100). When failures of such programs to include relevant critical perspectives and to react to criticism of their claims, methods and background assumptions are exposed, their claims to valid scientific knowledge (and to well-founded bases for social policy) can be refuted as not satisfying Longino's requirements for a knowledge-productive community. Thus, one is justified in refusing to accept their claims as knowledge.

It is important to stress that Longino's account does not require to restrict research programs by decision of an external official body. Longino's norms operate on the community level, wherein members of a knowledgeproducing community assess each other. Her criteria help to judge how se- 
riously knowledge claims and research programs that produce them should be taken. They stress the responsibility connected with participation in a Millian exchange of ideas. ${ }^{5}$ Failure to carry this responsibility-to adhere to the norms of criticism-results in the diminished credibility of claims in a community-wide discussion.

It is equally important to stress that Longino's criteria do not presuppose that a judgement requires some independent "objective" position. Making judgements of this kind is a part of interactive process of dialogue-based knowledge production: members of the community and members of other communities assess hypotheses and research programs when they draw upon them in their own work, or when they criticise them as a part of their work, or when they intentionally challenge particular research programs (like Longino 1990 did in her case studies). These judgements may in turn be challenged as a part of continuing debate. There is no absolute, immovable basis for objectivity in Longino's account and judgements about a community's objectivity are not absolute either. Her criteria describe the ideal conditions for objectivity; in practice, satisfaction of these criteria is a matter of degree. The more evident the failure of a particular research program to adhere to these norms, as assessed by members of relevant communities, the less credibility the research should be assigned.

Besides providing the criteria for exposing failures of objectivity in problematic research programs, Longino's account also opens additional possibilities for criticising these programs. Alongside evidential and methodological criticisms of a research program, it is possible to criticise the conceptual and metaphysical assumptions that shape it. This kind of criticism is more efficient if there exists a variety of alternative approaches. Longino provided several examples that show how alternative research programs help to make background assumptions visible. One such example is taken from research on sex differences: Longino (1990, 133-162) compared the behavioural neuroendocrinological program and the selectionist theory of higher brain function. Behavioural neuroendocrinology relies on assumptions about the duality of male-female brains and behavioural traits, and the direct link between prenatal exposure to sex hormones and these sex differences. The selectionist theory relies on assumptions about the continuum of variations in individual behaviour and about the plasticity of the brain that is partially shaped by individual intentional behaviour. In the presence of an alternative, the background assumptions of behavioural neuroendocrinology,

5 In her presentation of contextualism, Kristina Rolin (2008, 119-120) discussed Longino's ideas in parallel with Michael Williams's account of "default and challenge model". Longino's norms can also be seen as stressing the duty to defend or to modify one's beliefs if appropriately challenged. 
which have the potential for inegalitarian conclusions, can no longer be presented as self-evidently true.

The development of alternative research programs on the basis of assumptions that do not easily lend support to inegalitarian conclusions can thus expose problematic research programs in sociobiology and behavioural genetics. It may also help to change the assumptions that shape a field of research, leading to a new consensus about what constitutes proper approaches, relevant evidence and well-founded hypotheses. Kitcher $(2002,557)$ himself gave an example of such a change, in an area in which assumptions about sex and gender play a major role. During the time primatologists were mostly men, the dominant approach in primate studies focused one-sidedly on aggressiveness between male primates. When women began to enter the field, they focused on a wider range of behaviours. Kitcher explained this change in scientific practice as a result of the fact that for female scientists, different events were salient, enabling them to propose new hypotheses. I suggest that this development can be seen as a positive example that research based on alternative assumptions (an alternative vision of the field that makes particular events salient) may have some influence in a research area that is affected by sex and gender stereotypes and can reinforce them.

As described above, the Longinian solution to the problems of particular research programs depends on two conditions. One of them is diversity of community. In many cases, making problematic background assumptions visible is only possible in the presence of hypotheses based on alternative assumptions. Development of alternatives requires, in turn, that a variety of perspectives and ways of framing issues be represented in community. Underrepresentation of women and minorities in science and undervaluation of non-Western science constitute an epistemic problem because it reduces diversity in scientific community (Longino 2002, 132). This problem can only be remedied by inclusion of these mostly excluded groups.

The second condition requires adherence to certain criteria that encourage criticism and support its integration into a community's claims and background frameworks. If the social structure and practices of a particular scientific community discourage criticism and responsiveness to it, and if diversity of members is not appreciated as a cognitive resource but rather suppressed by the conditions of scientific education and career, increasing inclusiveness in science may not be sufficient. As Longino $(2002,132)$ stressed,

[The community] must do more than be open to the expression of multiple points of view; it must also take active steps to ensure that alternative points of view are developed enough to be a source of criticism and new perspectives.

So, in addition to taking action to ensure the adequate representation of un- 
derrepresented groups, as Brown proposed, it is equally important that the community creates conditions that can support cultivation of diverse perspectives and efficient transformative criticism. Longino's interest in developing normative criteria for communal dialogue recognises the point, which Kitcher also made, that in practice, what is called the Millian arena does not always function properly, and it is important to analyse what its proper functioning requires.

A solution based on Longino's approach would avoid some of the problems connected with Kitcher's argument, such as the tension between recognising a problem and implementing change without the threat of backlash. In Longino's account there is no such gap. The same set of criteria based on Longino's account of objectivity can be helpful for exposing problematic research programs and for addressing their problems. Furthermore, the approach based on Longino's account would avoid the problems Talisse and Aikin described in connection with the restrictions Kitcher proposedthe threat of proliferation of inequality-justifying research in the absence of counteracting research and the possible dampening effect on long-term planning of research. As there are no such restrictions in Longino's approach, it would not interfere with long-term planning in science and it actively encourages the development of alternative research programs that could counteract existing problematic ones. At the same time, Longino's approach addresses the question of the social consequences of research, which is omitted in Talisse and Aikin's defence of freedom of inquiry. In Longino's account, checks on the scientific and social consequences of research are provided through ongoing critical analysis of assumptions, including values and aims that frame research programs. So it is possible to recognise, and to tackle, the questions of social fairness that motivated Kitcher's argument.

However, there may be raised the question whether Longino's account of objectivity is sufficient to address the issues. In the following section I focus on several criticisms that have been presented in other discussions of Longino's work and are also relevant for the application of Longino's approach that I have been developing. I attempt to show that these arguments do not threaten the application of Longino's theory as a helpful approach to the problems with which Kitcher's argument is concerned.

\section{Some criticisms and replies}

\subsection{Long-term perspective}

Kitcher (1997, 296-297) stressed that Mill's argument takes a long-term view: "Mill recognises that the public presentation and discussion of false doctrines may detract from human welfare, but he supposes that this will be a short-term effect, and encourages us to take a longer view". Kitcher was 
concerned that unrestricted discussion and research might harm individuals and groups in the here and now.

The question of whether and to what degree a long-term perspective should be used, when considering knowledge production and its social consequences, also arises in connection with Longino's account. Her approach suggests a vision of communities that should endlessly develop toward greater objectivity, with her criteria as the regulatory ideal. It is possible that at some point, a community could develop the degree of objectivity and an ability to produce objective knowledge that enables efficient problemsolving strategies. However, this is insufficient if there is an immediate present need to tackle particular problems. The conflict between "longterm" philosophical thinking and the need to engage philosophy of science in urgent policy issues motivated Don Howard (2009) to argue for the reform of the current philosophy of science.

However, I suggest that Longino's approach makes possible such an engagement. If we recognise that background assumptions, including valueladen ones, inevitably serve as the frame for any hypothesis, we open up the possibility that hypotheses may be developed and presented in the framework of intentionally chosen assumptions that reflect particular commitments and values, for instance, a commitment to equality and social fairness. As Longino (1990, 191, emphasis added) wrote in her discussion of the possibility of feminist science,

We cannot restrict ourselves simply to the elimination of bias [as the value-free ideal of science would presuppose] but must expand our scope to include the detection of limiting interpretive frameworks and the finding or construction of more appropriate frameworks.

Accordingly, as a part of one's work as a scientist one may choose to create, or support, frameworks that are consistent with what one is committed to as, for instance, a feminist. (At the same time, according to Longino, such oppositional science should retain connection with the norms of scientific community, as presence of some shared standards is necessary for an alternative to be acknowledged in the community.) Like any others, hypotheses created in the context of such intentionally chosen assumptions should be subject to the relevant community's critical scrutiny. Longino's account of objectivity describes the conditions that help to make such scrutiny result in creation of intersubjectively acceptable knowledge. The same scrutiny should also be applied to existing research programs, and the emergence of intentionally different programs can in fact help to make political and ideological commitments behind the existing programs more visible. As Longino discussed these issues in connection with her own work on different conceptual models in research on sex differences, her argument may serve as a ready model 
for engaging with the fields with which Kitcher's argument is concerned, like human sociobiology.

Kitcher (2001) himself recently described a similar model for the discussion of the values that frame alternative hypotheses. This model constitutes a part of the further elaboration of the ideal of well-ordered science Kitcher has developed since introducing the concept in 2001. In Kitcher's (2011, 6162) example a concerned climate scientist might present scenarios of climate change together with considerations that frame them. This scientist might discuss the values that anticipated climate changes would endanger and the concurrent duty to prevent human suffering. The value framework presented by the climate scientist can be contrasted with alternatives, such as those values held by an industry partisan. Different value frameworks are to be judged according to their public acceptability in the ideal conversation that satisfies the conditions of mutual engagement. Would a particular framework be accepted in a conversation where all members of the human species take part, in which participants engage sympathetically with others, giving others' desires equal weight to their own, and the ultimate goal is to provide everyone with the best chance for a worthwhile life? Such an approach recognises the values that shape current research and argues for the possibility of intentionally embedding values in research in order to address urgent problems and advance communally acceptable values.

I thus suggest that Longino's account provides resources for immediate engagement with socially consequential research, and that some important similarities can be shown in both Longino's and recent Kitcher's strategies for such engagement.

\subsection{Objectivity}

Another potential problem in Longino's approach is related to her account of objectivity. As Sylvia Culp $(1995,440)$ summarised the problem, "even when dependence on idiosyncratic presuppositions is eliminated, dependence on the presuppositions shared by the entire community might not be".

Longino (e.g., 2002, 135) herself acknowledged this issue. Assumptions that are shared by all members of the community may remain invisible to criticism, no matter how inclusive the community. Or community members may not include potentially relevant perspectives because they are not available to them in practice, e.g., they are spatially and temporarily remote. Longino concluded that acceptance of knowledge claims and assumptions is always tentative. No matter how thorough intersubjective criticism may be, new criticism is always possible in principle. Longino's social objectivity thus has certain intrinsic limitations. They are not fixed-it is not given what assumptions may remain hidden from a community-but the possi- 
bility that some remain so is inescapable. I acknowledge this limitation of Longino's account.

However, I suggest that the limited character of objectivity does not endanger the application of her account that I have been describing. According to Longino (e.g., 2002, 134), objectivity is a matter of degree. Her criteria describe an ideal that serves as the basis for evaluating particular research programs and identifying their failures. So in practice, instead of focusing on the (im)possibility of absolute objectivity, one should focus on repairing particular failures of objectivity in particular communities. In many cases these can be easily recognised. For instance, in science, it is a well-known issue that women and other underprivileged groups are substantially underrepresented. As Longino noted, their underrepresentation is a particularly acute problem in case of research that is shaped by sexist and racist assumptionsin the absence of voices from the underprivileged groups, these assumptions remain unchallenged (Longino 1990, 78-79). Or, for instance, as Kitcher argued, the field of sociobiology has failed to acknowledge, and to react to, relevant and readily available criticism - the failure to adhere to the norm of uptake is prominent there. Additionally, a detailed critical exploration of particular programs may bring to light more subtle problems in connection with particular assumptions employed there. (Longino stressed repeatedly (e.g., 1990, 80-81 and 193-194) the importance of critical engagement that is local and focuses on particular research programs to analyse their assumptions in-depth.) The community should then focus on repairing lapses in objectivity that have been identified, improving objectivity in community "by degrees". In case of above examples, communities should take action to include relevant perspectives that are missing, or expose research programs that fail to support transformative criticism. As Longino's account is compatible with political (e.g., feminist) activism and actually encourages it, her account can be read as promoting in scientific community and wider society, in addition to critical analysis, action to improve inclusiveness, to cultivate formerly excluded perspectives and to improve responsiveness of scientific communities. ${ }^{6}$

${ }^{6}$ In her criticism of Longino's account, Janet Kourany (2010) put into doubt efficiency of such measures: according to her, scientific community historically was, and mostly remains, privileged and elitist. Even if the requirement of inclusiveness is heeded, the number of the underprivileged in science and their influence are severely limited, as they are selected and trained, and their working conditions and opportunities are shaped, by the privileged group with its "privilegecentric and privilegist" (Kourany 2010, 60) biases. However, as Kourany herself pointed out, in some cases greater presence of previously underrepresented groups in science has indeed led to emergence of alternative research that has influenced, or in some successful cases, displaced, previous biased programs. I suggest that although Longino's account cannot guarantee a full or immediate success politically and 
This strategy can help to address scientific and social issues that currently arise in connection with sociobiology and similar fields. According to the notion of objectivity by degrees, we can hope to improve objectivity of scientific communities by first addressing the lapses of objectivity that (at least some) community members or members of other relevant communities recognise at the moment. It is possible that the reformed community would still be characterised by some invisible assumptions and omissions to include relevant perspectives. Nonetheless, it may be more objective compared to the present state of the community and might have eradicated some of its present biases. Moreover, in this new state, lapses of objectivity that are not recognised now can become visible and thus become the new target for improving objectivity in a potentially endless development.

As Longino's account encourages attention to the currently recognised problems of objectivity and action to remedy them, I suggest that it could be useful for addressing the issues of particular research programs (the subject of Kitcher's argument), despite the fundamental limitations of communitybased objectivity.

\subsection{Sociality}

The final objection to Longino's account that I address was articulated by Justin Biddle (2009) and concerns the general nature of her account. Biddle argued that there is a contradiction between Longino's claim that objectivity is fundamentally social and the conception of individual her account presupposes. According to Biddle, Longino's norm of uptake is meant to operate on the level of individuals-for a community to adhere to the norm of uptake, most of its members should be responsive to criticism. Biddle argued that in Longino's account this responsiveness is in turn understood in the spirit of Millian liberalism as being "open to everything" (Biddle 2009, 618). Individuals are supposed to be capable of questioning any of their beliefs in response to any criticism from any perspective. However, such individuals, given their ultimate open-mindedness, are in principle capable of evaluating and criticising all of their beliefs on their own, without the need for input from other individuals. Thus, social interactions may be helpful but are not fundamentally necessary for objectivity-Longino's account is not truly social.

Contrary to Biddle's claim, I suggest that Longino's account does not rely on each individual's absolute openness to criticism. Longino (1990, 79) herself stated that in her account objectivity does not depend on particular atti-

epistemically, it can still be helpful for exposing failures of particular research programs, like those that concerned Kitcher, and encouraging change. 
tudes of individuals, "The objectivity of individuals in this scheme consists in their participation in the collective give-and-take of critical discussion and not in some special relation (of detachment, hardheadedness) they may bear to their observations". Thus, Longino did not treat one's detached, "open" attitude towards one's beliefs as necessary for community's objectivity. Later, Longino $(2002,147)$ characterised as inadequate the conception of a knowing subject as the "idealised Subject", "capable of the view from nowhere, the unconditioned (or universally conditioned) Subject". She stressed that her account presupposes knowing subjects that are embodied, socially located, and culturally conditioned. Such individuals are not capable of absolute openness Biddle described as the necessary basis of her account.

Instead, in her account the norm of responsiveness can be realised on the level of community (in Biddle' terms, it is social interpretation of uptake) thanks to particular social organisation of knowledge production and communication. Before an individual contribution is accepted as a part of public knowledge, it must necessarily pass critical scrutiny by others. Peerreview may be the most well known form of this scrutiny, but criticism also continues afterwards. In addition to direct critical challenge, individuals' claims may be modified by community in other ways-by attempts to replicate the results by other means, to use them in new contexts, to develop them further or to reconcile them with conflicting claims. These processes maintain objectivity of publicly accepted knowledge in the sense of blocking individual idiosyncrasies from entering public knowledge unchecked. The important feature of these processes is that they can operate efficiently on the communal level to a certain degree independently from individuals' attitudes towards their beliefs. It is possible that individuals question and modify their beliefs and assumptions after encountering criticism from others. It is also possible that their claims are taken up by others, modified and brought in accordance with a community's standards to become public knowledge, even if the authors of the claims do not accept these communitybased criticisms and modifications (see Longino 1990, 68-69 and 73-74, on absorption of individuals' claims into public knowledge). Some openness to criticism on part of each individual is necessary-one cannot be a member of a scientific community unless one is responsive to criticism enough to adhere to the requirements of peer-review. Yet, for a community to be objective, openness is not required to the absolute degree Biddle described. One's locatedness may limit one's ability to question deeply held assumptions or recognise them as such (though it may be possible). However, the social organisation of science makes it possible to use inevitably partial individual contributions for the collective production of intersubjectively acceptable knowledge. In this sense, Longino's account represents the very method of 
social scientific practice that Biddle himself defended.

\section{Conclusion}

Kitcher suggested that certain areas of research are influenced by political and epistemic asymmetries and are likely to produce conclusions that could have profoundly negative effects on underprivileged social groups. Accordingly, such research programs should not be continued. I have attempted to show that the issue of problematic research programs with far-reaching negative social consequences can be addressed without limiting freedom of speech. I have suggested that Longino's account can be used as the basis for addressing this issue. Longino developed an account of objective knowledge as emerging in the process of thorough intersubjective criticism of hypotheses and the background assumptions that frame them. Accordingly, if the scientific communities that produce the kind of research in question do not adhere to the criteria of inclusive and responsive criticism, and if their claims have not undergone critical scrutiny of a properly diverse community, their knowledge claims can be rejected as illegitimate. Simultaneously, Longino's account encourages the development of research programs based on alternative background assumptions committed to egalitarian values. Diverse communities and the support of conditions that encourage efficient dialogic criticism are the two crucial elements in the solution based on Longino's epistemological account.

In writing this paper, my aim has been to describe how Longino's account can be applied to the particular scientifico-political issues as Kitcher framed them and to address several criticisms that can be raised against such application. I hope to have shown that Longino's account of objectivity is robust enough to support tackling of these issues, that it allows for immediate engagement with them, and that accordingly, it can be helpful for addressing the epistemic and political concerns that motivated Kitcher's argument.

\section{Acknowledgements}

During the work on the paper, my work was partially funded from the grants ETF7946 and SFo180110so8. The previous versions of the paper were presented in 2011 at the event "Graduate Workshop with Philip Kitcher: Science and Democracy" at the University of Bielefeld and at the PhD colloquium of the Department of Philosophy in Tartu; I would like to thank the participants for helpful feedback. I would like to thank the anonymous reviewer for very detailed and helpful feedback. 


\section{Bibliography}

Biddle, J. B. (2009). Advocates or unencumbered selves? On the role of Mill's political liberalism in Longino's contextual empirism, Philosophy of Science 76: 612-623.

Brown, J. R. (2004). Science, Truth, and Democracy by Philip Kitcher, The Journal of Philosophy 101: 599-606.

Culp, S. (1995). Objectivity in experimental inquiry: Breaking datatechnique circles, Philosophy of Science 62: 430-450.

Feyerabend, P. K. (1991). Against Method, Verso, London.

Feyerabend, P. K. (1999). How to defend society against science, in J. Preston (ed.), P. K. Feyerabend. Knowledge, Science and Relativism: Philosophical Papers, Cambridge University Press, Cambridge, pp. 181-191.

Goldman, A. I. (1999). Knowledge in a Social World, Clarendon Press, Oxford.

Howard, D. (2009). Better red than dead-putting an end to the social irrelevance of postwar philosophy of science, Science \& Education 18: 199-220.

Kitcher, P. (1985). Vaulting Ambition: Sociobiology and the Quest for Human Nature, The MIT Press, Cambridge, MA.

Kitcher, P. (1997). An argument about free inquiry, Noûs 31: 279-306.

Kitcher, P. (2001). Science, Truth, and Democracy, Oxford University Press, New York.

Kitcher, P. (2002). The third way: Reflections on Helen Longino's The Fate of Knowledge, Philosophy of Science 69: 549-559.

Kitcher, P. (2007). Reply to Talisse and Aikin, Journal of Social Philosophy 38: 666-669.

Kitcher, P. (2011). Science in a Democratic Society, Prometheus Books, New York.

Kourany, J. A. (2010). Philosophy of Science after Feminism, Oxford University Press, Oxford.

Lloyd, E. A. (1997). Feyerabend, Mill, and pluralism, Philosophy of Science 64: S396-S407. Supplement. Proceedings of the 1996 Biennial Meetings of the Philosophy of Science Association. Part II: Symposia Papers.

Longino, H. (1990). Science as Social Knowledge: Values and Objectivity in Scientific Inquiry, Princeton University Press, Princeton.

Longino, H. (2002). The Fate of Knowledge, Princeton University Press, Princeton. 
Mill, J. S. (1978). On Liberty, Hacket Publishing Company Inc, Indianapolis.

Rolin, K. (2008). Science as collective knowledge, Cognitive Systems Research 9: 115-124.

Ryan, A. (1998). Mill in a liberal landscape, in J. Skorupski (ed.), The Cambridge Companion to Mill, Cambridge University Press, Cambridge, pp. 497-540.

Talisse, R. B. and Aikin, S. F. (2007). Kitcher on the ethics of inquiry, Journal of Social Philosophy 38: 654-665.

Wray, K. B. (2001). Science, biases, and the threat of global pessimism, Philosophy of Science 68: $\mathrm{S}_{467-S_{47}}$. Supplement: Proceedings of the 2000 Biennial Meeting of the Philosophy of Science Association. Part I: Contributed Papers. 